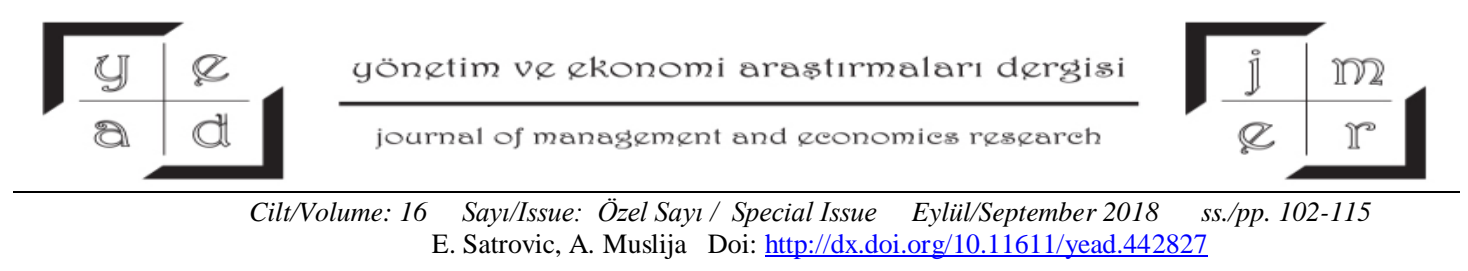

\title{
ECONOMIC AND DEMOGRAPHIC DETERMINANTS OF THE DEMAND FOR LIFE INSURANCE: MULTIVARIATE ANALYSIS
}

\author{
Asst. Prof. Elma SATrovic* id \\ Ph. D. (C.) Adnan MUSLIJA*
}

\begin{abstract}
The aim of this paper is to summarize a large number of economic and demographic determinants that are used to predict the demand for life insurance into a smaller number of component variables (components) and to determine which component has a stronger influence on demand for life insurance. Data are collected for 150 countries during the period 2005-2010. Final cross-country database is consisted of six-year average values on variables for selected countries. The methodology includes techniques of multivariate analysis: principal component analysis (PCA) and multiple linear regression. Results show that initial determinants of demand for life insurance can be summarized into two components: economic and demographic. Both components have a statistically significant positive influence on the demand for life insurance. On the basis of standardized regression coefficients it can be concluded that economic component is stronger determinant of demand for life insurance in comparison with demographic.
\end{abstract}

Keywords: Life Insurance Demand, Demographic Component, Economic Component, Multiple Linear Regression, Principal Component Analysis.

JEL Codes: G22; C31; E44.

\section{INTRODUCTION}

One of the most important decisions for individuals is whether to purchase life insurance. However, the process of making a decision regarding the purchase of life insurance as well as the choice of the most appropriate insurance product is complicated. Many consumers avoid this decision as they lack information about life insurance products. That is why it is crucial for life insurance companies to identify determinants that ought to influence consumers' demand for life insurance so they can help consumers to choose life insurance products that best suit to their personal needs.

\footnotetext{
* Çă̆ University, Yaşar Bayboğan Kampüsü, Adana-Mersin Karayolu üzeri, 33800 Yenice, Mersin, Turkey, e-mail: elmasatrovic@cag.edu.tr

*University of Sarajevo, Hazima Dedića 15b, Visoko, Bosnia and Herzegovina, e-mail: adnanmuslija@msn.com
} 
Life insurance companies are increasingly important players in financial systems. This insurance encourages long-term savings and the reinvestment of substantial amounts of money in public and private projects. Because of these characteristics, life insurance became very important stimulator of economic development (Haiss and Sumegi, 2008). Its role in stimulating economic development encouraged the research of life insurance demand's determinants.

Several studies have identified a set of determinants as good predictors of life insurance demand. Çelik and Kayali (2009); Beck and Webb (2003); Fortune (1973); Lewis (1989) and Munir et al. (2012) proved that income has the strongest positive influence on life insurance demand. Besides this, Beck and Webb (2003); Ward and Zurbruegg (2002); Çelik and Kayali (2009); Outreville (2015); Nesterova (2008); Munir et al. (2012); Sen (2008) and Haiss and Sumegi (2008) emphasize the importance of other economic determinants such as: inflation, real interest rate, savings, banking sector development as well as demographic variables namely: old dependency ratio, young dependency ratio, life expectancy, mean years of schooling and the share of urban to total population.

The paper is organized as follows: Literature review section summarizes results of empirical analyses. Research plan section explains research question and objectives, models specifications, data, methodology and research hypotheses. Results of research section presents the most important results of the estimated models. Paper ends with conclusion, appendices and references.

\section{LITERATURE REVIEW}

A theoretical framework for life insurance demand determinants has been derived for the first time by Yaari (1965) and Hakansson (1969). Yaari (1965) describes demand for life insurance as a function of wealth, expected income, the level of interest rates and the cost of life insurance policies (administrative costs). Demand is measured as a product of life insurance policies price and the number of policies sold. Today, life insurance companies base their calculation of life insurance price not only on this concept, since price consists of net-premium plus administrative and other costs, but also on additional determinants of life insurance demand which are mentioned further.

There is no single measure called "life insurance demand". This is why this research presents 2 proxy variables that are commonly used to measure life insurance demand. Those are life insurance penetration and life insurance density. Life insurance penetration is defined as the ratio of premium volume to GDP, while life insurance density is defined as premium per capita (Beck and Webb, 2003).

After defining life insurance demand, it is necessary to describe determinants that could be used to predict life insurance demand. The most common determinants are: income level, inflation, private savings rate, real interest rate, banking sector development, young dependency ratio, old dependency ratio, life expectancy, mean years of schooling, the share of urban to total population and social security expenditure. 
Life insurance consumption should rise with the level of income. The main reason is that an individual's consumption and human capital typically increase along with income, which increases demand for life insurance as well. Level of income is approximated by GDP per capita. Lee (2015); Tien and Young (2014); Sliwinski et al. (2013); Munir et al. (2012); Medeiros Garcia (2012); Lee et al. (2010); Çelik and Kayali (2009) and Beck and Webb (2003) proved positive relationship between income measured by GDP per capita and life insurance demand. The same authors prove that higher social security expenditure increases desire for life insurance since citizens have feeling of higher level of wealth. Life insurance products are savings products. This is why positive influence of savings on life insurance demand is expected. Munir et al. (2012) and Outreville (2015) prove that higher savings rate increases the demand for life insurance.

Banking sector development is expected to be positively correlated with life insurance consumption. Tien and Young (2014); Sliwinski et al. (2013); Munir et al. (2012); Sen (2008) and Beck and Webb (2003) show that well-functioning banks may increase the confidence consumers have in other financial institutions, e.g. life insurance companies. More stable banks can help life insurers to invest more efficiently, which also may increase consumer's confidence.

Inflation is expected to have a negative relationship with life insurance consumption since monetary uncertainty negatively influences savings products' expected returns. Negative influence is proved by Yang et al. (2015); Çelik and Kayali (2009); Haiss and Sumegi (2008); Sen (2008); Beck and Webb (2003) and Ward and Zurbruegg (2002). However, Chang et al. (2014) and Outreville (2015) prove that inflation does not have statistically significant influence on life insurance demand. Since, there is no clear conclusion regarding the influence of inflation on life insurance demand, inflation is used as control variable.

The effect of interest rates is ambiguous. Higher interest rate leads to the higher profitability of insurers (Outreville, 2015; Nesterova, 2008 and Munir et al. 2012). But at the other side the increase in interest rates might reduce the purchase of life insurance because higher returns on alternative assets may switch consumers from life insurance to other type of savings (Beck and Webb, 2003). This is why this variable is used as control.

Young dependency ratio represents the ratio between young dependents and working population. High dependency ratio indicates there is too young population to save substantial amounts for retirement, and therefore reduces demand for life insurance products (Outreville, 2015; Nesterova, 2008; Sen, 2008 and Beck and Webb, 2003). Medeiros Garcia (2012) and Lee et al. (2010) prove that young dependency ratio has statistically insignificant influence on life insurance demand. This is why this variable is used as control. At the other side a higher ratio of old dependents to working population is expected to increase life insurance demand. Beck and Webb (2003) prove that in countries with a higher share of retired population, life insurance as savings products are important financial products. 
Life expectancy - The life insurance companies base actuarial price estimations on the life expectancy at birth. It is expected that longer life expectancy stimulates accumulation of more capital through savings, and thus increase life insurance product's demand (Outreville, 2015; Nesterova, 2008; Haiss and Sumegi, 2008; Beck and Webb, 2003).

Schooling - The level of a person's education may determine his/her ability to understand the benefits of risk management and savings. A higher level of education might increase an individual's level of risk aversion, and thus increase the desire for protection thru life insurance products (Medeiros Garcia, 2012; Lee et al., 2010; Nesterova, 2008; Haiss and Sumegi, 2008; Beck and Webb, 2003 and Munir et al., 2012).

Economies with a higher share of urban to total population are expected to have higher levels of life insurance consumption. The explanation is: urban population is more aware and has more income to buy life insurance products (Outreville, 2015; Nesterova, 2008; Beck and Webb, 2003 and Munir et al., 2012)

\section{RESEARCH PLAN}

\subsection{Research Question and Objectives}

The research question is whether the economic component is stronger determinant of life insurance demand comparing to demographic component? 3 objectives of the research are defined. The first objective is to summarize a large number of economic and demographic determinants that are used to predict life insurance demand, into a smaller number of component variables. Second objective is to determine which component has a stronger influence on the demand for life insurance. Third objective is to predict life insurance demand by using component and control variables.

\subsection{Hypotheses of Research}

Based on research question, primary research hypothesis is identified: economic component is stronger determinant of demand for life insurance comparing to demographic component. Secondary research hypotheses are also defined. Those are:

(1) Economic component gives the best presentation of life insurance demand's determinant GDP per capita.

(2) Demographic component gives the best presentation of life insurance demand's determinant mean years of schooling.

(3) Inflation does not have statistically significant influence on life insurance demand. 
Yönetim ve Ekonomi Arasttrmaları Dergisi / Journal of Management and Economics Research

Cilt/Volume: $16 \quad$ Sayl/Issue: Özel Sayl/Special Issue Eylül/September 2018 ss./pp. 102-115

E. Satrovic, A. Muslija Doi: http://dx.doi.org/10.11611/yead.442827

\subsection{Data and Model Specification}

The availability of the data on life insurance was the main criteria while creating a database. The second most import criteria was to include more countries compared to research to date. Lastly, the aim was to eliminate year bias that could appear if the measurement is performed only in one year. Hence, the initial database consisted of 155 countries, 14 independent variables in the period between 2005 and 2010.

Five countries had more than 50\% missing data and were eliminated from the database, as well as two independent variables. Before performing multivariate analysis, the presence of missing data was tested for remaining 150 countries, 12 independent and one dependent variable. Variables social security expenditure, the share of urban to total population, banking sector development and savings had missing data up to $5 \%$ of the total number of cases. Little's Missing Completely at Random Test (MCAR) was used to test the randomness of missing data. MCAR proves that all missing data are completely at random. This is why Expectation-maximization technique based on maximum likelihood is used for imputation.

Life insurance demand is measured by using life insurance premium per capita. Determinants of demand are divided into: general and control determinants. Further, general determinants are divided into economic (GDP per capita, social security expenditure, banking sector development, savings) and demographic (life expectancy, share of urban to total population, mean years of schooling and old dependency ratio). These determinants are used in principal component analysis (PCA). Control determinants that are used are: inflation, interest rate and young dependency ratio. In addition, it is explored whether the region influences the differences in demand for life insurance by countries. These variables are used in multiple regression analysis. Main independent variables in linear regression models are components.

The basis for the selection of variables are following papers: Lee (2015); Tien and Young (2014); Nesterova (2008); Sen (2008); Beck and Webb (2003); and Ward and Zurbruegg (2002). A detailed description of variables, data sources and measurement units are given in Appendix 2. Data were collected for 150 countries (Appendix 1) in the period 2005-2010. Final cross-country database consists of six-year average values on data for selected countries.

\subsection{Methodology}

This research uses secondary numerical data that are considered to be measured objectively, and that are collected by different international institutions (Swiss Re, The World bank, UNDP). Also, data are measured at different scales, and descriptive statistics indicates that the variable GDP per capita would be much more influential comparing to other variables. This indicates the need for standardization 
of data. Therefore, factor analysis is not considered appropriate rather the PCA on correlation matrix in order to summarize determinants into a smaller number of component variables.

The second part of analysis uses multiple linear regression and OLSE (Ordinary Least Square estimator). This analysis is used to predict life insurance demand measured by life premium per capita (dependent variable). Independent variables are components scores calculated by PCA and control variables. Multiple regression analysis will be also used to determine which of the components has a stronger influence on life insurance demand. Since the dependent variable is quantitative and independent variables are quantitative and qualitative as well, multiple regression analysis is considered to be adequate technique. Taking into account the objectives of the research and the characteristics of variables, it is believed that other methods of multivariate analysis would not be appropriate in this paper.

\section{RESULTS OF RESEARCH}

PCA uses following determinants of life insurance demand: GDP per capita, social security expenditure, banking sector development, savings, old dependency ratio, life expectancy, share of urban to total population and mean years of schooling. The aim of PCA is to determine whether the observed determinants can be summarized into a smaller number of component variables that will explain high percentage of initial determinant's variance.

Correlation coefficients within economic as well as demographic determinants of life insurance demand are high and positive (none is below 0.4). However, correlations between groups of determinants exist but are lower comparing to correlations within groups. PCA requires that KMO measure of sample adequacy exceeds 0.5 for each variable as well as for set of variables. Anti-image correlation matrix indicates that every individual measure of sample adequacy exceeds 0.5 , so these variables can be retained in analysis. In addition, KMO measure of sample adequacy for set of variables equals 0.829 and is considered adequate. PCA requires statistically significant Barlett sfericity test. $p$ value of Barlett's sfericity test in this case equals 0.000. Taking into consideration correlation coefficients, KMO measure of sample adequacy and Barlett sfericity test, it can be concluded that PCA can be applied on aforementioned economic and demographic components.

The next step in analysis is to determine the number of components that should be retained. Kaiser's rule is used for this purpose. The results suggest that 2 components have eigen values above 1, so 2 components should be retained. Graph 1 (scree plot - Appendix 3), confirms these results. Retained components explain $80.031 \%$ of initial determinant's variance which is in accordance with Hair et al. (2009). Results before rotation indicate that some variables have high correlations with both components. The first component has strong correlation coefficients with all of the variables. In order 
to improve interpretability of results, orthogonal varimax rotation is used. It is assumed that components are independent, this is why varimax rotation is considered appropriate according to Hair et al. (2009).

Eigen values after rotation indicate that component 1 contains the same amount of information as 3.486 variables, component 2 as 2.917 variables, i.e. 2 component variables contain more information than 5 initial determinants. The rotated component matrix (Table 1) shows correlation coefficients between extracted components and initial determinants. Economic determinants have practically significant loadings only on component 1 . This is why component 1 is called "economic". Demographic determinants have practically significant loadings only on component 2 . This is why component 2 is called "demographic". Practically significant loading is this $\geq \pm 0.50$ according to Hair et al. (2009). GDP per capita is variable that is the best presented by economic component (component loading equals 0.919 - Table 1) which indicates no rejection of secondary research hypothesis 1. Mean years of schooling is the variable that is the best presented by demographic component (component loading equals 0.849 - Table 1) which indicates no rejection of secondary research hypothesis 2 .

10 countries with the highest values of economic and demographic components scores are identified. Those are:

\begin{tabular}{ll}
\hline $\begin{array}{l}\text { Rank } \\
\text { (economic } \\
\text { component) }\end{array}$ & Country \\
\hline 1 & Japan \\
2 & Luxembourg \\
3 & Denmark \\
4 & Switzerland \\
5 & Netherlands \\
6 & Iceland \\
7 & Germany \\
8 & Norway \\
9 & Hong Kong \\
10 & USA. \\
\hline Rank & \\
$($ demographic & Country \\
component) & \\
\hline 1 & Japan \\
2 & Sweden \\
3 & Germany \\
4 & Belgium \\
5 & Australia \\
6 & Switzerland \\
7 & United Kingdom \\
8 & Norway \\
9 & Denmark \\
10 & Netherlands. \\
&
\end{tabular}

For 10 countries selected in the first table economic component is stronger determinant of life insurance demand comparing to average countries in analysis. For example, economic component score for Japan indicates that economic component is 2.649 standard deviations stronger determinant of life insurance demand comparing to average countries in analysis. World Bank database indicates that 
aforementioned 10 countries are high-income countries. For 10 countries selected in second table, demographic component is stronger determinant of life insurance demand comparing to average countries in analysis. Descriptive analysis indicates that selected countries have the largest individual values of demographic determinants which justifies obtained results. According to Sigma reports (Swiss Re), Japan has the most developed life insurance industry in the world measured by life insurance premium per capita. Thus, the best ranking according to both components is expected. Table 1 summarizes results of PCA.

Communality shows the percentage of initial determinant's variance that is explained by selected components. All obtained communalities are above 0.5 (Table 1). For example economic and demographic components explain $98.1 \%$ of variability of GDP per capita. There are different methods that can be used for calculating components scores. However, regression, Bartlett scores or AndersonRubin method provide same results in the case of PCA. This analysis uses regression method. Component scores range between \pm 3.0 , which indicates no outliers in this analysis (Singhal and Anilk, 2000).

Table 1.Component Loadings after Orthogonal Rotation (PCA) ${ }^{1}$

\begin{tabular}{|l|lll|}
\hline Determinant/variable & $\begin{array}{l}\text { Economic } \\
\text { component }\end{array}$ & $\begin{array}{l}\text { Demograp } \\
\text { hic } \\
\text { component }\end{array}$ & $\begin{array}{l}\text { Communa } \\
\text { lity }\end{array}$ \\
\hline GDP per capita & $\mathbf{0 . 9 1 9}$ & 0.369 & 0.981 \\
Banking sector development & $\mathbf{0 . 8 8 6}$ & 0.294 & 0.872 \\
Social security expenditure & $\mathbf{0 . 8 6 0}$ & 0.271 & 0.814 \\
Savings & $\mathbf{0 . 8 8 7}$ & 0.357 & 0.914 \\
Old dependency ratio & 0.310 & $\mathbf{0 . 7 5 4}$ & 0.665 \\
Life expectancy & 0.313 & $\mathbf{0 . 8 1 3}$ & 0.759 \\
Mean years of schooling & 0.271 & $\mathbf{0 . 8 4 9}$ & 0.795 \\
Share of urban to total & 0.245 & $\mathbf{0 . 7 3 7}$ & 0.603 \\
population & 43.573 & 36.458 & 80.031 \\
\hline Explained variance $(\%)$ & &
\end{tabular}

Extraction method: Principal component analysis (PCA)

Rotation: Varimax with Kaiser Normalization.

In order to identify which component is stronger explanatory variable of demand for life insurance, multiple linear regression models are estimated by using OLS (Ordinary Least Squares) estimator in software Stata 12. 10 models are estimated. All assumptions (Field, 2005) except homoscedasticity are satisfied in models (1)-(10). In order to overcome this problem, Huber/White robust estimator is used in this case. Table 2 provides model's results estimated by Huber/White robust estimator.

The dependent variable is life insurance premium per capita in USD, while independent variables are components obtained in PCA (column 1, Table 2). Low correlation coefficients between variables in multiple regression models are recorded, i.e. PCA has resolved the problem of strong correlations

\footnotetext{
${ }^{1}$ Sources of all tables and graphs in this paper are author's calculations. 
between variables. Since PCA provides standardized values of components, dependent variable is standardized as well in order to improve interpretability. Besides components, regression analysis includes dummy variable for region, standardized values of inflation; interest rates and young dependency ratio as control variables (columns 2-10, Table 2). Hierarchical method of multiple linear regression is used. 10 models are estimated. Table 2 presents results obtained if Stata 12 after resolving the problem of heteroscedasticity. The first model is basic regression model. Other 9 models include additional determinants in order to test do these determinants change significantly explanatory power of the initial model.

Table 2. Determinants of Life Insurance Demand - Standardized Life Insurance Premium Per Capita is Used as a Measure of Demand (Cross-Country Data, Period 2005-2010, Huber/White Robust Estimator)

\begin{tabular}{|c|c|c|c|c|c|c|c|c|c|c|}
\hline & (1) & (2) & (3) & (4) & (5) & (6) & (7) & (8) & (9) & (10) \\
\hline Economic & 0.709 & 0.687 & 0.691 & 0.713 & 0.709 & 0.686 & 0.712 & 0.690 & 0.652 & \\
\hline Demographic & 0.340 & 0.326 & 0.329 & 0.343 & 0.341 & 0.326 & 0.343 & 0.328 & & -0.478 \\
\hline component & $(0.066)^{*}$ & $(0.068)^{*}$ & $(0.070)^{*}$ & $(0.067)^{*}$ & $(0.070)^{*}$ & $(0.072)^{*}$ & $(0.070)^{*}$ & $(0.073)^{*}$ & & $(0.333)$ \\
\hline & & -0.054 & -0.050 & & & -0.054 & & -0.050 & & \\
\hline Inflation & & $(0.040)$ & (0.044) & & & $(0.040)$ & & $(0.044)$ & & \\
\hline Interest rate & & & 0.017 & 0.027 & & & 0.027 & 0.018 & & \\
\hline 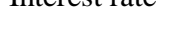 & & & $(0.036)$ & $(0.033)$ & & & $(0.038)$ & $(0.041)$ & & \\
\hline Young depen. & & & & & -0.003 & -0.003 & -0.003 & -0.006 & & \\
\hline Ialio & & & & & & & & & -0.272 & -0.982 \\
\hline Africa & & & & & & & & & $(0.126)^{*}$ & $(0.811)^{*}$ \\
\hline Oceania & & & & & & & & & -0.071 & -0.201 \\
\hline & & & & & & & & & $(0.209)^{* *}$ & $(0.915)$ \\
\hline Asia & & & & & & & & & $\begin{array}{l}-0.312 \\
(0217)^{*}\end{array}$ & $\begin{array}{l}-0.751 \\
(0860) * *\end{array}$ \\
\hline North & & & & & & & & & -0.243 & -0.763 \\
\hline America & & & & & & & & & $(0.132)^{*}$ & $(0.714)^{*}$ \\
\hline South & & & & & & & & & 0.020 & 0.016 \\
\hline America & & & & & & & & & $(0.270)$ & $(0.513)$ \\
\hline F test & $34.00^{*}$ & $28.82^{*}$ & $21.78^{*}$ & $23.24^{*}$ & $22.51^{*}$ & $21.64^{*}$ & $16.68^{*}$ & $17.37^{*}$ & $35.75^{*}$ & $11.60^{*}$ \\
\hline $\mathrm{R}^{2}$ & 0.619 & 0.621 & 0.622 & 0.620 & 0.620 & 0.621 & 0.620 & 0.621 & 0.586 & 0.256 \\
\hline $\begin{array}{l}\text { Number of } \\
\text { obs. }\end{array}$ & 147 & 147 & 147 & 147 & 147 & 147 & 147 & 147 & 147 & 147 \\
\hline
\end{tabular}

standard errors - represented in parentheses.

$*$,** significant at $99 \%$ and $95 \%$ respectively.

Column (1) - results of basic regression model indicate that regression coefficients with economic and demographic components are statistically significant at 99\%. The obtained coefficients are standardized regression coefficients. Standardized coefficients indicate that economic component (0.709) has stronger influence on life insurance demand comparing to demographic (0.340). Interpretations of coefficients are as follows: if the economic component increases by 1 standard deviation, demand measured by life insurance premium per capita will increase by 0.709 standard deviations on average ceteris paribus. On the other hand the increase in demographic component by 1 standard deviation increases life insurance demand by 0.340 standard deviations on average ceteris paribus. 
Column (2) shows results with the inclusion of the first control variable (inflation). Both components are statistically significant. Inclusion of inflation decreases the coefficients with both components i.e. decreases the strength of component's influence comparing to model 1 . The inclusion of interest rate (column 4) increases coefficients with both components comparing to model (1). Combination of inflation and interest rate has similar effects as model (2).

Young dependency ratio (column 5) as the only control variable does not change the coefficient with economic component but increases coefficient with demographic by 0.001 comparing to model (1). This variable in combination with inflation (column 6) decreases coefficients with both components. Opposite results are obtained when young dependency ratio is combined with interest rate (column 7). Column (8) shows that the combination of 3 numeric control variables decreases the strength of influence of both components.

Interest rate, inflation and young dependency ratio do not have statistically significant influence on life insurance demand in models (2)-(8) which indicates no rejection of secondary research hypothesis 3. The obtained results are in accordance with Beck and Webb (2003). Models (2)-(8) indicate small changes in coefficients of determination comparing to basic regression model. It can be concluded that control variables do not improve significantly predictive power of basic regression model (Table 2).

The summary of the models (1)-(8) indicates the highest regression coefficients with economic component. Standardized regression coefficients indicate that economic component has stronger statistically significant positive influence on life insurance demand comparing to demographic. Based on this result primary research hypothesis can't be rejected. In addition it can be concluded that economic component is more vulnerable to the effects of economic control variables (inflation and interest rate) while demographic component is more vulnerable to the effect of young dependency ratio.

Models (9) and (10) show does the region of country has a significant influence on life insurance demand and regression coefficients with components. European countries are used for comparison. Results of model (9) indicate that for countries located in Africa, Asia, Oceania and North America region has statistically significant impact on economic component and life insurance demand. On average life insurance demand in these countries is lower comparing to demand in European countries. Demographic component becomes statistically insignificant when region variable is included. Model (10) has low explanatory power. Initially models (9) and (10) do not provide standardized regression coefficients. This is why standardized coefficients were calculated in advance and presented in Table 2 .

Characteristics of standardized data indicate the exclusion of constant term. Constant does not have practical significance. $F$ test proves that models in Table 2 are statistically significant. Coefficients of determination (Table 2) indicate that models (1-8) explain about $62 \%$ of variability of life insurance demand. Beck and Webb (2003) and Nesterova (2008) obtain coefficients of determination that range 
between 60 and $65 \%$. These papers use the same variables listed in this research. Small changes in coefficients of determination prove statistically insignificant influence of control variables on life insurance demand (Table 2).

Models (1)-(10) satisfy assumptions of linear regression explained in Field (2005) except for the assumption of homoscedasticity. PCA resolves the problem of multicollinearity (models (1)-(10) have VIF values $<10$ ). Independent variables are not correlated with residuals. This analysis uses crosscountry data. This is why assumptions of no autocorrelation and stationarity can't be rejected. JarqueBera test of normality and histogram obtained in Stata 12 are used to test the distribution of residuals and prove that distribution does not differ from normal. Observations are independent. Statistically significant statistics of Breusch-Pagan and White's tests indicate the presence of heteroscedasticity. Huber/White robust estimator is used to overcome this problem. Huber/White robust estimator does not change values of regression coefficients rather standard errors. This estimator does not provide values of adjusted coefficient of determination.

\section{CONCLUSION}

The aim of this paper was first to use PCA to identify this determinant that strongly affects the demand for life insurance. Results indicate that eight initially used economic and demographic determinants of life insurance demand can be summarized into two component variables that explain $80.031 \%$ of initial determinant's variance. GDP per capita is variable that is the best presented by economic component which indicates no rejection of secondary research hypothesis 1 . Mean years of schooling is variable that is the best presented by demographic component which indicates no rejection of secondary research hypothesis 2 (Table 1 ).

The second part of analysis uses components obtained in PCA and additional control variables to predict the demand for life insurance and determine which component has a stronger influence on the demand. 10 regression models are estimated. The first model indicates that both components have a statistically significant positive influence on life insurance demand, but the economic component has stronger influence. Models (2)-(8) analyze do control variables change significantly regression coefficients with components. All models indicate that economic component has stronger statistically significant influence on life insurance demand comparing to demographic which indicates no rejection of primary research hypothesis. The influence of interest rate, inflation and young dependency ratio on life insurance demand is not statistically significant in models (2)-(8) which indicates no rejection of secondary research hypothesis 3 . In addition it can be concluded that economic component is more vulnerable to the effects of economic control variables (inflation and interest rate) while demographic component is more vulnerable to the effect of young dependency ratio. Coefficients of determination (Table 2) indicate that models (1-8) explain about $62 \%$ of variability of life insurance demand. 
Results of model (9) indicate that for countries located in Africa, Asia, Oceania and North America region has statistically significant impact on economic component and life insurance demand. On average life insurance demand in these countries is lower comparing to demand in European countries. Demographic component becomes statistically insignificant when region variable is included. Model (10) has low explanatory power.

These results are expected taking into consideration the characteristics of life insurance. Satrovic (2018) summarizes these characteristics as following: life insurance policies are specific financial products important not only for policyholders, insured and insurers but also for the economy as a whole since these enable the accumulation of long-term funds that can be used for investment. Moreover, the great importance of economic determinant can be justified by the fact that life insurance development is directly proportional to the standard of living and the level of national income. Citizens of highincome countries are able to allocate larger amount of money on life insurance products. In addition, motivation for savings increases as the level of income increases. On the other hand, citizens of lowincome countries have in general low standard of living due to the low income, so then hardly save or buy life insurance.

The results of this paper are primarily directed to actuaries who need to pay a great attention to economic as well as demographic determinants while creating insurance policies. Moreover, this paper highlights the need for actuaries to gather the data on income level and regions in order to encourage the efficiency of policies. These results are also important since they indicate that gap between countries in the globalizing world can be reduced by the means of financial institutions (Dağ, et al. 2018).

Hence, the recommendation for future research is to take into account the potential impact of the financial crisis of 2007-2008. Due to life insurance's role as a financial intermediary, there is a necessity to explore whether or not the stock market development plays moderating role between variables of interest.

\section{REFERENCES}

Arena, M. (2006) “Does Insurance Market Activity Promote Economic Growth? A Cross-Country Study for Industrialized and Developing Countries", The World Bank.

Beck, T. and Webb, I. (2003) "Economic, Demographic, and Institutional Determinants of Life Insurance Consumption across Countries', The World Bank Economic Review, 17(1): 51-88.

Chang, T., Lee, C.C. and Chang, C.H. (2014) "Does Insurance Activity Promote Economic Growth? Further Evidence Based on Bootstrap Panel Granger Causality Test', The European Journal of Finance, 20: 1187-1210. 
Curak, M., Dzaja, I. and Pepur, S. (2013) "The Effect of Social and Demographic Factors on Life Insurance Demand in Croatia“, International Journal of Business and Social Science, 4(9): 65-72.

Çelik, S. and Kayali, M.M. (2009) "Determinants of Demand for Life Insurance in European Countries", Problems and Perspectives in Management, 7: 32-37.

Dağ, M., Kizilkaya, O. and Demez, S. (2018) "Samaritan Çıkmazı Bağlamında Dış Yardımların Ekonomik Büyümeye Etkisinin İncelenmesi: Ampirik Bir Analiz’, Maliye Araştırmaları Dergisi, 4(1): 17-25.

Field, A. (2005) “Discovering Statistics Using SPSS”, SAGE Publications.

Fortune, P. (1973) “A Theory of Optimal Life Insurance: Development and Test”, The Journal of Finance, 28(3): 587-600.

Hair, J.F., Black, W.C., Babin, B.J and Anderson, R.E. (2009) "Multivariate Data Analysis", Pearson.

Haiss, P. and Sumegi, K. (2008) "The Relationship of Insurance and Economic Growth-A Theoretical and Empirical Analysis. Empirica', Journal of Applied Economics and Economic Policy, 35(4): 405-431.

Hakansson, N. H. (1969) “Optimal Investment and Consumption Strategies under Risk, an Uncertain Lifetime, and Insurance'”, International Economic Review, 10(3): 443-466.

Lee, F. (2015) “An Empirical Analysis on Quantity Demand of Life İnsurance in China", Proceedings of 2014 1st International Conference on Industrial Economics and Industrial Security 2015, 241-247.

Lee, S.J., Kwon, S. and Chung, S.Y. (2010) "Determinants of Household Demand for Insurance: The Case of Korea", The Geneva Papers, 35: S82-S91.

Lewis, E. D. (1989) "Dependents and the Demand for Life Insurance”, American Economic Review, 79(3): 452-467.

Kline, P. (1999) “The Handbook of Psychological Testing”, Routledge.

McFadden, D. (1974) “Conditional Logit Analysis of Qualitative Choice Behavior”, Academic Press: New York

Medeiros Garcia, M.T. (2012) "Determinants of the Property-Liability Insurance Market: Evidence from Portugal', Journal of Economic Studies, 39: 440-450.

Munir, S., Khan, A. and Jamal, A. (2012) "Impacts of Macroeconomic \& Demographic Variables on the Demand of Life Insurance: A case Study of State Life Insurance Corporation of Pakistan (1973-2010)", University of Management and Technology, Lahore, Pakistan. 
Nesterova, D. (2008) "Determinants of the Demand for Life Insurance: Evidence from Selected CIS and CEE Countries", National University “Kyiv-Mohyla Academy”.

Outreville, J. F. (1996) "Life Insurance Markets in Developing Countries", Journal of Risk and Insurance, 63(2): 263-278.

Outreville, J.F. (2015) "The Relationship between Relative Risk Aversion and the Level of Education: a Survey and Implications of the Demand for Life Insurance', Journal of Economic Surveys, 29: 97-111.

Satrovic, E. (2018) "Merits of Life Insurance”, Munich: GRIN Verlag.

Sen, S. (2008) "Insurance in India: Determinants of Growth and the Case of Climate Change', TERI University.

Singhal, R. and Anilk, M. (2000) "Environmental Issues and Management of Waste in Energy and Mineral Production', Balkema.

Sliwinski, A., Michalski, T. and Roszkiewicz, M. (2013) "Demand for Life Insurance-An Empirical Analysis in the Case of Poland', The Geneva Papers, 38: 62-87.

Tien, J.J. and Yang, S.S. (2014) “The Determinants of Life Insurer's Growth for a Developing Insurance Market: Domestic vs. Foreign Insurance Firms", The Geneva Papers, 39: 1-24.

Ward, D. and Zurbruegg, R. (2002) "Law, Politics and Life Insurance Consumption in Asia", Geneva Papers on Risk and Insurance, 27(3): 395-412.

Yaari, M. E. (1965) “Uncertain Lifetime, Life Insurance and the Theory of the Consumer', Review of Economic Studies, 32(2): 137-150.

Yang, S.Y., Li, H.A. and Fang, H.C. (2015) "The Non-Linear Relationship between Economic and Life Insurance Development in Asia: A Panel Threshold Regression Analysis“, Springer, 330: $1281-1290$. 